\title{
Suboptimal prenatal screening of Chlamydia trachomatis and Neisseria gonorrhoeae infections in a Montréal birthing and tertiary care centre: $A$ retrospective cohort study
}

\author{
Victoria Ivensky ${ }^{1}$, Romain Mandel ${ }^{1,2}$, Annie-Claude Boulay ${ }^{1}$, Christian Lavallée ${ }^{1,3,4}$, Janie Benoît ${ }^{5}$, \\ Annie-Claude Labbé ${ }^{1,3,4 *}$
}

\begin{abstract}
Background: The Canadian Paediatric Society no longer recommends the use of universal ocular prophylaxis with erythromycin ointment to prevent ophthalmia neonatorum. Screening for Chlamydia trachomatis and Neisseria gonorrhoeae in all pregnant women is considered the most effective way of preventing vertical transmission and ophthalmia neonatorum.
\end{abstract}

Objective: The aims of this study were to assess prenatal screening rates of $C$. trachomatis and $N$. gonorrhoeae and to compare sociodemographic factors between those screened and those not screened.

Methods: The list of all women who delivered at a tertiary care hospital in Montréal, Québec, between April 2015 and March 2016, was cross-referenced with the list of samples tested for C. trachomatis and N. gonorrhoeae. Maternal medical records were reviewed for demographic, prenatal and diagnostic information.

Results: Of 2,688 mothers, 2,245 women were screened at least once, but only 2,206 women had at least one valid $C$. trachomatis and $N$. gonorrhoeae result the day of delivery (82.1\%; 95\% Cl: 80.6\%-83.5\%). Infection was detected in 46/2,206 (2.1\%) screened women: 42 had C. trachomatis infection, two had N. gonorrhoeae infection and two were co-infected. C. trachomatis infection was more frequent in women younger than 25 years $(9.8 \% ; 95 \% \mathrm{Cl}$ : $6.7 \%-13.8 \%)$ than in older women $(0.8 \% ; 95 \% \mathrm{Cl}: 0.4 \%-1.3 \% ; p<0.001)$. Each increase in parity decreased the probability of being tested (adjusted odds ratio $=0.89 ; 95 \% \mathrm{Cl}: 0.80 \%-0.97 \%$; $p=0.01)$. Of those with an initial negative test result, 35/267 (13.1\%; 95\% Cl: $9.3 \%-17.8 \%)$ of women younger than 25 years and 122/1,863 (6.6\%; $95 \% \mathrm{Cl}: 5.5 \%-7.8 \% ; p<0.001)$ of women aged 25 years and older were retested. Subsequent infection was detected in $4 / 35$ (11\%) women, all younger than 25.

Conclusion: Suboptimal screening rates for $C$. trachomatis and $N$. gonorrhoeae suggest that current universal ocular prophylaxis cannot be discontinued. Repeating universal screening should be considered, especially among those younger than 25 years.
This work is licensed under a Creative Commons Attribution 4.0 International License.

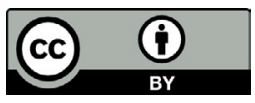

Affiliations

${ }^{1}$ Faculty of Medicine, Université de Montréal, Montréal, QC

2 Department of Paediatrics, Hôpital Maisonneuve-Rosemont, CIUSSS de l'Est-de-l'île-deMontréal, Montréal, OC

${ }^{3}$ Department of Microbiology, Infectious Diseases and Immunology, Université de Montréal, Montréal, QC

${ }^{4}$ Division of Infectious Diseases and Medical Microbiology, Hôpital Maisonneuve-Rosemont, CIUSSS de l'Est-de-l'île-deMontréal, Montréal, QC

${ }^{5}$ Department of Obstetrics and Gynecology, Hôpital Maisonneuve-Rosemont, CIUSSS de l'Est-de-l'île-de-Montréal, Montréal, QC

\section{*Correspondence:}

ac.labbe@umontreal.ca

Suggested citation: Ivensky V, Mandel R, Boulay AC, Lavallée C, Benoît J, Labbé AC. Suboptimal prenatal screening of Chlamydia trachomatis and Neisseria gonorrhoeae infections in a Montréal birthing and tertiary care centre: A retrospective cohort study. Can Commun Dis Rep 2021;47(4):209-15.

https://doi.org/10.14745/ccdr.v47i04a05

Keywords: chlamydia, gonorrhea, screening, pregnancy, prenatal, Montréal

\section{Introduction}

Chlamydia trachomatis and Neisseria gonorrhoeae are the two most common bacterial sexually transmitted infections (STIs) and a major public health concern $(1,2)$. When an infected pregnant woman is left untreated, vertical transmission can occur at the time of delivery. This may result in ophthalmia neonatorum and cause permanent corneal damage $(3,4)$. 
The American Academy of Pediatrics and the Québec Ministry of Health and Social Services recommend the use of universal ocular prophylaxis with erythromycin ointment $0.5 \%$ at birth for neonatal gonococcal ophthalmia (5-8). However, N. gonorrhoeae strains isolated in Canada have shown increasing resistance to erythromycin in the past few years, with $31 \%(n=1,642)$ of the 5,290 isolates tested in 2017 showing resistance. It is unclear whether neonatal gonococcal ophthalmia can be overcome with high local antibiotic levels during prophylaxis $(9,10)$.

With the efficacy of erythromycin ointment in doubt, the Canadian Paediatric Society (CPS) and equivalent organizations in several high-income countries no longer recommend its universal use (10-12). Instead, for primary prevention of neonatal infections, CPS advocates prenatal screening and treatment of infected women. As $77 \%$ of C. trachomatis and $45 \%$ of $N$. gonorrhoeae infections are asymptomatic, routine screening is critical for diagnosing and treating those infected (13).

In order to prevent neonatal gonococcal ophthalmia, the Public Health Agency of Canada (PHAC) and CPS recommend that all pregnant women be screened for $C$. trachomatis and $N$. gonorrhoeae infections during the first trimester. Those at risk of acquiring infection later in pregnancy should be retested each trimester (PHAC) or in the third trimester (CPS), with treatment, test of cure and follow-up ensured in the event of a positive test result $(6,10,14)$.

Although Manitoba and Ontario recently assessed the prevalence of $C$. trachomatis and $N$. gonorrhoeae infections and screening rates during pregnancy, these rates remain unknown in Québec, a province where $23 \%$ of all births in Canada were recorded in 2016 (15-17). In light of an eventual abrogation of universal ocular prophylaxis, the aim of this study was to:

- Determine sociodemographic characteristics of pregnant women in a tertiary care hospital in Montréal

- Assess prenatal screening rates

- Determine prevalence of C. trachomatis and N. gonorrhoeae infection in pregnant women

- Compare sociodemographic factors between those screened at least once for $C$. trachomatis and N. gonorrhoeae and those who were not screened

\section{Methods}

In this cohort study, we performed a retrospective review of the medical records of all women who gave birth to newborns of at least 19 weeks' gestation (live and stillbirths) at Hôpital Maisonneuve-Rosemont, a tertiary care hospital in Montréal, between April 1, 2015 and March 31, 2016.

The medical records included the clinical data during pregnancy of each woman who had given birth (age at delivery and cigarette, drug and alcohol use); obstetric history (gravidity, parity, abortus and date of last menstrual period); pregnancy follow-up (specialty of the health practitioner, date of first prenatal visit); and delivery (gestational age and type of delivery). Date of the last menstrual period was calculated according to date of delivery and gestational age at delivery, which takes into consideration the prenatal ultrasound results.

We obtained the list of all women who delivered during the study period from the hospital medical records department and the list of HIV and C. trachomatis and N. gonorrhoeae tests performed at the hospital laboratory during that period and nine months prior. Using STATA version 14.2 (StataCorp LP, College Station, Texas, United States), we cross-referenced the two lists, based on the health insurance number of each woman, retaining only the tests performed during pregnancy. In cases where no C. trachomatis and N. gonorrhoeae test was performed at the hospital's laboratory, the chart was reviewed for tests performed in other laboratories in Québec. We also searched for mentions of screening test completion in the pregnancy follow-up chart notes.

We considered the women adequately screened if they had at least one valid $C$. trachomatis and $N$. gonorrhoeae result (positive or negative) during pregnancy follow-up, before the day of delivery. If a test had been ordered, but no result was available (specimen rejected by the laboratory, invalid result, etc.) and no additional sample was collected at follow-up, the woman was not considered screened during pregnancy. If we found no documentation of prenatal care and no screening tests for HIV or C. trachomatis and $N$. gonorrhoeae at least one week before delivery, the woman was considered to have had no pregnancy follow-up. This also applies to women who were only followed outside of Canada or in other provinces until one week before delivery.

We used the Pearson Chi-square test to analyze categorical data (with statistical significance set at $p \leq 0.05$ ). Each variable associated with screening at $p \leq 0.20$ in the univariable analysis was considered for the multivariable logistic regression model, which was constructed using a forward design, retaining only age and variables that increased the model fit.

This study was approved by the Ethics Committee of the Centre intégré universitaire de santé et de services sociaux (CIUSSS) de l'Est-de-l'île-de-Montréal.

\section{Results}

\section{Sociodemographic characteristics of the study population}

The study included 2,688 pregnant women aged 15-50 years (median age $=31.7$; interquartile range $=7.4$ ). Table 1 shows the sociodemographic distribution of the study population. 
Table 1: Characteristics of the study population

\begin{tabular}{|c|c|c|}
\hline Maternal characteristics & $\%$ & $\mathbf{n}$ \\
\hline \multicolumn{3}{|l|}{ Age at delivery $(\mathrm{N}=2,688)$} \\
\hline $15-19$ years & 2.0 & 55 \\
\hline $20-24$ years & 10.9 & 292 \\
\hline $25-29$ years & 25.8 & 694 \\
\hline 30-34 years & 35.3 & 949 \\
\hline $35-39$ years & 20.5 & 551 \\
\hline $40+$ years & 5.5 & 147 \\
\hline \multicolumn{3}{|l|}{ Gravidity $(N=2,678)$} \\
\hline 1 & 30.6 & 820 \\
\hline 2 & 30.7 & 822 \\
\hline 3 & 19.0 & 510 \\
\hline $4+$ & 19.6 & 526 \\
\hline \multicolumn{3}{|l|}{ Parity $(\mathrm{N}=2,678)$} \\
\hline 0 & 46.5 & 1,246 \\
\hline 1 & 32.7 & 876 \\
\hline 2 & 14.4 & 386 \\
\hline 3 & 4.3 & 116 \\
\hline $4+$ & 2.0 & 54 \\
\hline \multicolumn{3}{|l|}{ Maternal habits } \\
\hline Smoking $(N=2,575)$ & 10.7 & 276 \\
\hline Alcohol $(\mathrm{N}=2,569)$ & 2.3 & 60 \\
\hline Drugs $(\mathrm{N}=2,571)$ & 2.5 & 65 \\
\hline$\geq 1$ habit $(N=2,688)$ & 12.1 & 324 \\
\hline
\end{tabular}

At least one prenatal clinical visit was documented in the medical chart of 2,661/2,688 (99\%) women: 1,571 (58\%) were followed by an obstetrician-gynecologist (OBGYN); 1,062 (40\%) by a general practitioner (GP) and $3(0.1 \%)$ by the organization Doctors of the World. We could not find information about health practitioners for 25 (0.1\%) women; of these, seven were followed in another country.

Of the 2,633 (98\%) women who were followed either by a GP or an OBGYN during pregnancy, 2,312 (87.8\%) had their first prenatal visit in the first trimester (1-14 gestational weeks), 280 $(10.6 \%)$ in the second trimester (15-28 weeks) and $41(1.6 \%)$ in the third trimester (29-42 weeks).

\section{Screening for Chlamydia trachomatis and Neisseria gonorrhoeae infections in pregnancy}

No screening test was ordered during pregnancy follow-up for $443 / 2,688$ (16.5\%) of the women (Figure 1). Of the 74 women whose first sample was rejected by the laboratory or gave an invalid C. trachomatis and N. gonorrhoeae result, 35 (47.3\%) were retested and obtained a valid result. Final screening rate was estimated at $82.1 \%(2,206 / 2,688 ; 95 \%$ confidence interval [Cl]: 80.6\%-83.5\%).
Figure 1: Proportion of women screened for Chlamydia trachomatis and Neisseria gonorrhoeae infections during pregnancy, before the day of delivery

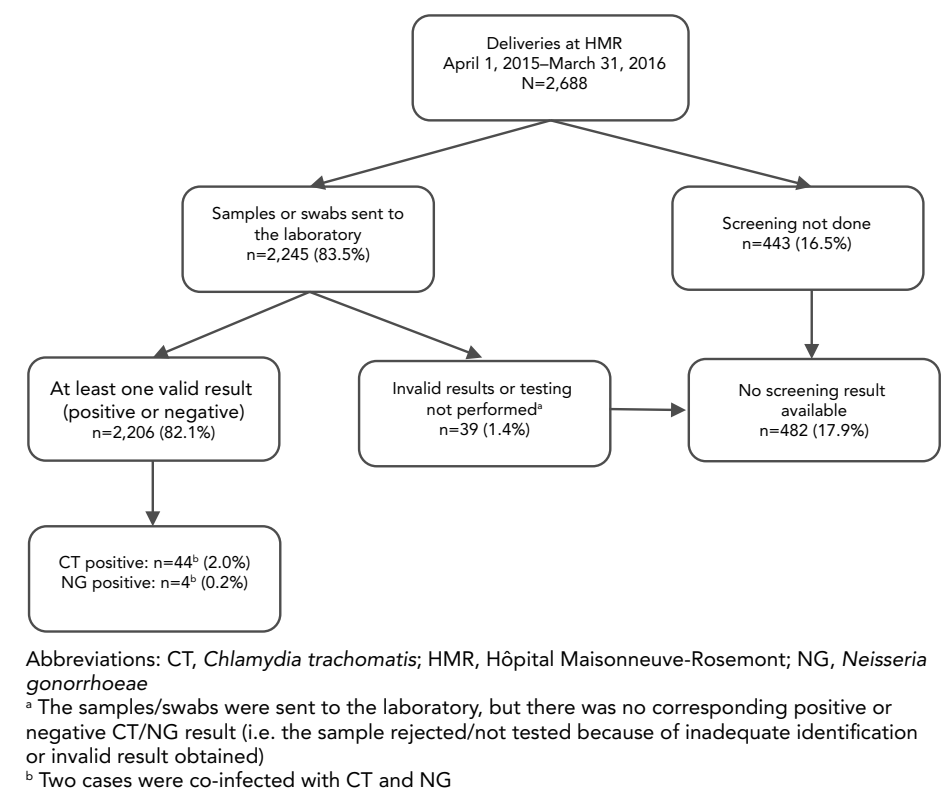

Of the 482 women who were inadequately screened during pregnancy follow-up, 22 (4.6\%) were screened at the time of delivery.

\section{Prevalence of infection in pregnancy}

Infection was detected in 46/2,206 (2.1\%) screened women: 42 had $C$. trachomatis infection, two had N. gonorrhoeae infection and two were infected with both. Prevalence of C. trachomatis was estimated at $2.0 \%(95 \% \mathrm{Cl}: 1.5 \%-2.7 \%)$ and of N. gonorrhoeae at $0.2 \%$ ( $95 \% \mathrm{Cl}: 0.005 \%-0.5 \%)$. Women younger than 25 years were more likely to have $C$. trachomatis infection (29/296; 9.8\%; 95\% Cl: 6.7\%-13.8\%) than those aged 25 years and older (15/1,910; $0.8 \% ; 95 \% \mathrm{Cl}: 0.4 \%-1.3 \%$; $p<0.001)$. Prevalence of $N$. gonorrhoeae infection was also significantly higher in younger women ( $1.0 \%$ vs $0.05 \% ; p<0.001)$.

Of the 2,130 women with an initial negative test result for C. trachomatis and N. gonorrhoeae, 157 (7.4\%) were retested: $35 / 267$ of women younger than 25 years (13.1\%; 95\% Cl: 9.3\%-17.8\%) and 122/1,863 of women aged 25 years and older (6.6\%; $95 \% \mathrm{Cl}: 5.5 \%-7.8 \% ; p<0.001)$. A subsequent infection for $N$. gonorrhoeae was detected in one woman (age 23 years) and for $C$. trachomatis in three women (ages 19, 24 and 24 years). In other words, 11.4\% (4/35; 95\% Cl: 3.2\%-26.7\%) of women aged $15-24$ years with an initial negative test result tested positive at their second screening. 


\section{Sociodemographic factors associated with screening}

Screening rates for $C$. trachomatis and $N$. gonorrhoeae were slightly higher in women younger than 25 years $(296 / 347 ; 85.3 \%$; 95\% Cl: 81.1\%-88.9\%) than among older women (1,910/2,341; $81.6 \% ; 95 \% \mathrm{Cl}: 80.0 \%-83.1 \% ; p=0.09)$. Globally, as shown in Figure 2, the association between maternal age and prenatal screening was statistically significant $(p=0.04)$, but the difference across age groups was marginal (Table 2 and Table 3 ).

Figure 2: Chlamydia trachomatis and Neisseria gonorrhoeae screening rates, by maternal age

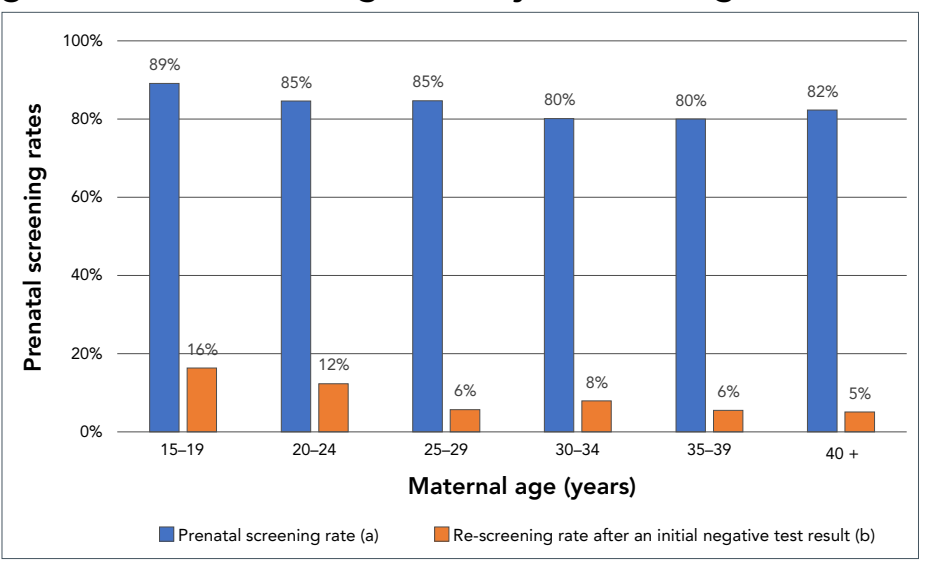

Table 2: Sociodemographic characteristics of screened and non-screened pregnant women

\begin{tabular}{|c|c|c|c|c|c|}
\hline \multirow{2}{*}{\multicolumn{2}{|c|}{ Description }} & \multicolumn{2}{|c|}{$\begin{array}{l}\text { Screened }^{a} \\
(n=2,206)\end{array}$} & \multicolumn{2}{|c|}{$\begin{array}{l}\text { Not screened } \\
\qquad(n=482)\end{array}$} \\
\hline & & Median & SD & Median & SD \\
\hline \multicolumn{2}{|l|}{ Age } & 31.5 & 5.4 & 32.4 & 5.1 \\
\hline \multicolumn{2}{|c|}{ Maternal characteristics } & $\mathbf{n}$ & $\%$ & $\mathbf{n}$ & $\%$ \\
\hline \multirow{2}{*}{ Smoking } & Yes $(n=276)$ & 234 & 11 & 42 & 9.4 \\
\hline & No $(n=2,299)$ & 1,896 & 89 & 403 & 90.6 \\
\hline \multirow{2}{*}{ Alcohol } & Yes $(n=60)$ & 50 & 2.3 & 10 & 2.3 \\
\hline & No $(n=2,509)$ & 2,076 & 97.7 & 433 & 97.7 \\
\hline \multirow{2}{*}{ Drugs } & Yes $(n=65)$ & 60 & 2.8 & 5 & 1.2 \\
\hline & No $(n=2,504)$ & 2,068 & 97.2 & 438 & 98.8 \\
\hline \multirow{2}{*}{$\geq 1$ habit } & Yes $(n=324)$ & 274 & 12.4 & 50 & 10.4 \\
\hline & No $(n=2,364)$ & 1,932 & 87.6 & 432 & 89.6 \\
\hline \multirow{3}{*}{$\begin{array}{l}\text { First } \\
\text { prenatal } \\
\text { visit }\end{array}$} & $\begin{array}{l}\text { First trimester } \\
(n=2,329)\end{array}$ & 1,932 & 87.6 & 397 & 87.3 \\
\hline & $\begin{array}{l}\text { Second } \\
\text { trimester } \\
(n=288)\end{array}$ & 239 & 10.8 & 46 & 10.1 \\
\hline & $\begin{array}{l}\text { Third trimester } \\
(n=47)\end{array}$ & 35 & 1.6 & 12 & 2.6 \\
\hline \multirow{2}{*}{$\begin{array}{l}\text { Medical } \\
\text { specialty }\end{array}$} & $\begin{array}{l}\text { OBGYN } \\
(n=1,571)\end{array}$ & 1,308 & 59.4 & 263 & 61.0 \\
\hline & $G P(n=1,062)$ & 894 & 40.6 & 168 & 39.0 \\
\hline
\end{tabular}

Table 3: Odds ratios of prenatal screening for chlamydial and gonococcal infections in relation to maternal sociodemographic characteristics $(n=2,688)$

\begin{tabular}{|c|c|c|c|c|c|c|}
\hline $\begin{array}{c}\text { Maternal } \\
\text { characteristics }\end{array}$ & $\begin{array}{l}\text { Odds } \\
\text { ratio }\end{array}$ & $95 \% \mathrm{Cl}$ & $\underset{\text { value }}{p}$ & $\begin{array}{c}\text { Adjusted } \\
\text { odds } \\
\text { ratio }^{a}\end{array}$ & $95 \% \mathrm{Cl}$ & $\stackrel{p}{p}$ \\
\hline $\begin{array}{l}\text { Age } \\
\text { (continuous) }\end{array}$ & 0.97 & $(0.96-0.99)$ & 0.006 & 0.99 & $(0.97-1.01)$ & 0.17 \\
\hline Smoking & 1.18 & $(0.84-1.67)$ & 0.30 & N/A & N/A & N/A \\
\hline Alcohol & 1.04 & $(0.52-2.07)$ & 0.90 & N/A & N/A & $\mathrm{N} / \mathrm{A}$ \\
\hline Drugs & 2.54 & $(1.01-6.37)$ & 0.04 & 2.35 & $(0.93-5.94)$ & 0.09 \\
\hline$\geq 1$ habit & 1.23 & (0.89-1.69) & 0.20 & $\mathrm{~N} / \mathrm{A}$ & N/A & $\mathrm{N} / \mathrm{A}$ \\
\hline $\begin{array}{l}\text { Prenatal visit in } \\
\text { first trimester }\end{array}$ & 0.92 & $(0.71-1.18)$ & 0.50 & N/A & N/A & N/A \\
\hline $\begin{array}{l}\text { OBGYN follow- } \\
\text { up }^{b}\end{array}$ & 1.07 & $(0.87-1.32)$ & 0.50 & N/A & N/A & N/A \\
\hline $\begin{array}{l}\text { Gravidity (per } \\
\text { additional } \\
\text { pregnancy) }\end{array}$ & 0.92 & $(0.87-0.98)$ & 0.01 & N/A & N/A & N/A \\
\hline $\begin{array}{l}\text { Parity (per } \\
\text { additional } \\
\text { delivery) }\end{array}$ & 0.83 & $(0.75-0.90)$ & $<0.001$ & 0.89 & $(0.80-0.97)$ & 0.01 \\
\hline \multicolumn{7}{|c|}{$\begin{array}{l}\text { Abbreviations: } \mathrm{Cl} \text {, confidence interval; OBGYN, obstetrician-gynecologist; N/A, not applicable } \\
\text { a Each variable associated with screening with a p value } \leq 0.20 \text { in the univariable analysis was } \\
\text { considered for the multivariable model. This multivariable model was constructed using a forward } \\
\text { design, retaining only age and variables that increased the model fit } \\
\text { b In comparison to general practitioner follow-up }\end{array}$} \\
\hline
\end{tabular}

Screening rates were also higher at low parity and gravidity and in women who used drugs. After multivariate analysis, parity was the only factor associated with higher prenatal screening rate: each additional pregnancy decreased the odds of being tested for $C$. trachomatis and $N$. gonorrhoeae (adjusted odds ratio $[a O R]=0.89$; 95\% Cl: 0.80\%-0.97\%; $p=0.01$ ) (Table 3).

Prenatal screening rates were identical for GPs $(894 / 1,062$; $84.2 \%$; $95 \% \mathrm{Cl}: 81.8 \%-86.3 \%)$ and OBGYNs $(1,308 / 1,571 ; 83.3 \%$; $95 \% \mathrm{Cl}: 83.1 \%-85.1 \%)$.

\section{Discussion}

In our study, the median age of the pregnant women was 32 years. The majority of women had their first prenatal visit in the first trimester ( $88 \%$ ) and were followed by an OBGYN (58\%) or GP (40\%). Prenatal screening rate was $82 \%$ and prevalence of infection was estimated at $2.0 \%$ for $C$. trachomatis and $0.2 \%$ for $N$. gonorrhoeae. Low parity was the sole sociodemographic factor associated with higher screening rates.

Our findings are similar to those of previous studies. Vainder et al. investigated records for 1,220 pregnancies over a 6-month period in 2015-2016 (16). Of these, 1,034 (85\%) pregnant women in a tertiary care hospital in Toronto were screened at least once during pregnancy. Poliquin et al. found that $78 \%$ $(45,601 / 58,488)$ of live births in Manitoba in 2011-2014 were associated with at least one prenatal test for $C$. trachomatis and N. gonorrhoeae (17). 
In a tertiary care hospital in Bordeaux, France, over 6-month period in 2011, Peuchant et al. estimated prevalence of C. trachomatis at $2.5 \%$ and $N$. gonorrhoeae at $0 \%$ in 1,004 pregnant women (18). At 7.9\%, prevalence of $C$. trachomatis was reported to be higher in women aged 18-24 years, a finding similar to ours (9.4\%). The maternal age distribution at delivery and the proportion of women who smoked during pregnancy in our study population are comparable to the rates found in the total population of pregnant women in Canada $(19,20)$.

\section{Strengths and limitations}

Some medical charts had incomplete information on maternal habits, pregnancy follow-up and obstetric or past medical history, eliciting a potential risk of selection bias.

Maternal age younger than 25 years and substance use (alcohol and drugs) were the sole STI risk factors available in the study; maternal STI risk behaviours are rarely specified in medical charts (14). Yet, some clinicians could have used a risk factor-based approach to decide which women to screen, rather than testing all pregnant women. We therefore could not thoroughly evaluate what led clinicians to screen some women rather than others.

Finally, the study was conducted in a single hospital and accounted for about $3 \%(2,688 / 86,000)$ of all births in Québec in 2016 (15). A multicentric study would increase generalizability to the province of Québec.

In terms of the strengths of our study, in addition to laboratory software extraction, we reviewed medical charts to capture screening tests analyzed in other laboratories. We also took into account rejected or invalid screening tests as well as subsequent retesting to obtain a valid result.

This is the first Canadian study to evaluate screening and prevalence of infection in pregnancy after an initial negative test result, helping to provide a more accurate portrait of prenatal screening. High prevalence of $C$. trachomatis infection in women aged 15-24 years in our study highlights the importance of screening this high-risk age group. High prevalence was also found at their second screening (11.4\%), after an initial testing negative, further confirming that a first negative result does not guarantee absence of infection throughout the entire pregnancy (21).

Suboptimal screening rates suggest that universal ocular prophylaxis cannot currently be discontinued. If we extrapolate our findings to the province of Québec, with 86,000 annual deliveries in 2016, around 15,000 neonates could be born to women who had not been adequately screened during pregnancy (15). Assuming that the prevalence of infection is similar in the whole province, that the prevalence is similar in women who are screened and those who are not and that there is no spontaneous clearance of infection, our finding of a C. trachomatis infection rate of $2.0 \%$ and a $N$. gonorrhoeae infection rate of $0.2 \%$ in pregnant women would mean that 300 C. trachomatis and $30 \mathrm{~N}$. gonorrhoeae infections would be missed each year. With a $30 \%$ and $40 \%$ rate of vertical transmission to the eye for C. trachomatis and N. gonorrhoeae, respectively, each year 102 neonates would be expected to have C. trachomatis and N. gonorrhoeae ophthalmia (22).

Apart from the increased risk for serious systemic complications, abrogation of universal ocular prophylaxis would also increase the risk of neonates developing ophthalmia neonatorum, which can lead to permanent visual impairment $(3,4,23,24)$. The newborns of 15,000 unscreened women in Québec would therefore have to be closely monitored for infection every year.

Changes in screening practices could prevent such outcomes. Increasing the use of self-administered swabs could contribute to increased screening, particularly by those who are not comfortable with clinician sampling and those who are asymptomatic (25).

In order to confirm absence of infection later in pregnancy, a second universal $C$. trachomatis and $N$. gonorrhoeae screening of all women should be considered in the third trimester. In addition to identifying women who become infected later in pregnancy, an examination of a prenatal syphilis screening program in Alberta found that this strategy reduced the number of women who are not screened for disease during pregnancy (26).

Although screening at entry into prenatal care and at another time point during pregnancy (such as the third trimester) would be the costliest strategy, doing so would provide the greatest health benefits. This screening strategy would be cost-effective if the willingness-to-pay threshold was under $\$ 11,468$ per quality-adjusted life-year (QALY) (27).

\section{Conclusion}

Suboptimal screening rates for $C$. trachomatis and $N$. gonorrhoeae in pregnant women raise concerns about discontinuation of ocular prophylaxis for ophthalmia neonatorum. Ocular prophylaxis will continue to be necessary to prevent ophthalmia neonatorum as long as universal screening cannot be guaranteed. Clinicians need to be more aware of the importance of universal screening in pregnant women and further encouraged to document test results in medical charts.

\section{Authors' statement}

$\mathrm{ACL}$ - Conceptualization, methodology, funding acquisition, formal analysis, visualization, statistical analysis, project administration, supervision, writing-review \& editing ACB - Investigation, writing-review \& editing $\mathrm{CL}$ - Software, investigation, formal analysis, writing-review \& editing 
JB - Conceptualization, writing-review \& editing RM - Conceptualization, methodology, formal analysis, visualization, supervision, writing-review \& editing $\mathrm{VI}$ - Conceptualization, investigation, data curation, formal analysis, data interpretation, statistical analysis, funding acquisition, investigation, writing-original draft, visualization

\section{Competing interests}

$A C L$ is a member of the National Advisory Committee on STBBI (CCN-ITSS) of the Public Health Agency of Canada, as well as of the Committee on STBBI (CITSS) of the Institut national de santé publique du Québec. The opinions expressed in this article are those of the author and do not necessarily reflect those of these committees.

\section{Acknowledgements}

The authors thank S Bélanger and S Beauchemin for helping with our submission to the Ethics Committee, N Frappier for laboratory extractions and Sophia Aouinati and Marie-Claude Drouin for constructive discussions when planning the study.

Part of our results were presented at the STI \& HIV 2019 World Congress - Joint meeting of the 23rd International Society for STD Research (ISSTDR) \& 20th International Union against Sexually Transmitted Infections (IUSTI) in Vancouver (BC), on July 16, 2019: Screening rates and follow-up of Chlamydia trachomatis and Neisseria gonorrhoeae infections during pregnancy. The abstract was published in Sex Transm Infect 2019; 95(Suppl 1):A219.

We also presented our results at the following meetings:

- The AMMI Canada - CACMID Annual Conference in Ottawa on April 4, 2019: Prenatal Screening of Chlamydia trachomatis and Neisseria gonorrhoeae Infections: Sufficiently Reliable to Abrogate Topical Ocular Prophylaxis to Newborns?

- $\quad$ Santé publique 2018, ACSP, Montréal (QC), May 31, 2018. Dépistage prénatal des infections à Chlamydia trachomatis (CT) et Neisseria gonorrhoeae (NG) : peut-on s'y fier pour cesser la prophylaxie oculaire aux nouveau-nés?

\section{Funding}

This research was supported by a scholarship from the "Programme d'Excellence en Médecine pour l'Initiation En Recherche" (PREMIER) awarded to VI. The sponsor had no role in the design and conduct of the study; the collection, management, analysis and interpretation of the data; preparation, review or approval of the manuscript; and decision to submit the manuscript for publication. The opinions, results, and conclusions are those of the authors.

\section{References}

1. Public Health Agency of Canada. Case definitions: nationally notifiable diseases. Ottawa (ON): Government of Canada; (modified 2019-09-25). http://diseases.canada.ca/notifiable/ diseases-list

2. Public Health Agency of Canada. Reported cases from 1991 to 2018 in Canada - notifiable diseases on-line. Ottawa (ON): Government of Canada; (modified 2019-09-25; accessed 2021-02-09). http://diseases.canada.ca/notifiable/charts?c=yl

3. Schaller UC, Klauss V. Is Credé's prophylaxis for ophthalmia neonatorum still valid? Bull World Health Organ 2001;79(3):262-3. PubMed

4. Mordhorst $\mathrm{CH}$, Dawson $\mathrm{C}$. Sequelae of neonatal inclusion conjunctivitis and associated disease in parents. Am J Ophthalmol 1971;71(4):861-7. DOI PubMed

5. Prévention de la conjonctivite néonatale au Québec : À propos. Québec $(\mathrm{QC})$ : Ministère de la Santé et des Services sociaux; (modified 2017-07-13; accessed 2021-02-09). http://www.msss.gouv.qc.ca/professionnels/perinatalite/ prevention-de-la-conjonctivite-neonatale/a-propos/

6. Kimberlin DW, Brady MT, Jackson MA, editors. Red Book (2018): Report of the Committee on Infectious Diseases. 31 edition. Itasca (IL): American Academy of Pediatrics Committee on Infectious Diseases; 2018.

7. Abalos E, Chamillard M, Diaz V, Tuncalp Ö, Gülmezoglu AM. Antenatal care for healthy pregnant women: a mapping of interventions from existing guidelines to inform the development of new WHO guidance on antenatal care. BJOG 2016;123(4):519-28. DOI PubMed

8. Curry SJ, Krist AH, Owens DK, Barry MJ, Caughey AB, Davidson KW, Doubeni CA, Epling JW Jr, Kemper AR, Kubik M, Landefeld CS, Mangione CM, Silverstein M, Simon MA, Tseng CW, Wong JB; US Preventive Services Task Force. Ocular Prophylaxis for Gonococcal Ophthalmia Neonatorum: US Preventive Services Task Force Reaffirmation Recommendation Statement. JAMA 2019;321(4):394-8. DOI PubMed

9. Public Health Agency of Canada. National surveillance of antimicrobial susceptibilities of Neisseria gonorrhoeae in Canada: annual summary 2017. Ottawa (ON): Government of Canada; (modified 2019-05-01; accessed 2021-02-09). https://www.canada.ca/en/public-health/services/ publications/drugs-health-products/national-surveillanc e-antimicrobial-susceptibilities-neisseria-gonorrhoeae-annua I-summary-2017.html

10. Moore DL, MacDonald NE; Canadian Paediatric Society, Infectious Diseases and Immunization Committee. Preventing ophthalmia neonatorum. Paediatr Child Health 2015;20(2):93-6. PubMed 
11. Hammerschlag MR, Cummings $C$, Roblin PM, Williams $T H$, Delke I. Efficacy of neonatal ocular prophylaxis for the prevention of chlamydial and gonococcal conjunctivitis. N Engl J Med 1989;320(12):769-72. DOI PubMed

12. Neonatal ocular prophylaxis: shortage of erythromycin ophthalmic ointment for use in newborns. Ottawa (ON): Canadian Paediatric Society; (modified 2019-02-19; accessed 2021-02-09). https://www.cps.ca/media/neonatal-ocula r-prophylaxis-shortage-of-erythromycin-ophthalmic -ointment-for-use-in-newborns

13. Farley TA, Cohen DA, Elkins W. Asymptomatic sexually transmitted diseases: the case for screening. Prev Med 2003;36(4):502-9. DOI PubMed

14. Public Health Agency of Canada. Canadian guidelines on sexually transmitted infections. Ottawa (ON): Government of Canada; (modified 2020-07-09; accessed 2021-02-09). https://www.canada.ca/en/public-health/services/ infectious-diseases/sexual-health-sexually-transmittedinfections/canadian-guidelines/sexually-transmittedinfections.html\#toc

15. Statistics Canada. Fertility: overview, 2012 to 2016 . Ottawa (ON): Government of Canada; (modified 2018-06-11; accessed 2021-02-09). https://www150.statcan.gc.ca/n1/ pub/91-209-x/2018001/article/54956-eng.htm

16. Vainder M, Kives S, Yudin MH. Screening for gonorrhea and chlamydia in pregnancy: room for improvement. J Obstet Gynaecol Can 2019;41(9):1289-94. DOI PubMed

17. Poliquin V, Wylie J, Cole R, Yudin MH, Van Caesseele P. Preparedness for implementing change in neonatal ocular prophylaxis policies. J Obstet Gynaecol Can 2016;38(1):7-8. DOI PubMed

18. Peuchant O, Le Roy C, Desveaux C, Paris A, Asselineau J, Maldonado C, Chêne G, Horovitz J, Dallay D, de Barbeyrac B, Bébéar C. Screening for Chlamydia trachomatis, Neisseria gonorrhoeae, and Mycoplasma genitalium should it be integrated into routine pregnancy care in French young pregnant women? Diagn Microbiol Infect Dis 2015;82(1):14-9. DOI PubMed
19. Statistics Canada. Live births, by age of mother. Ottawa (ON): Government of Canada; (modified 2019-11-22; accessed 2021-02-09). DOI

20. Public Health Agency of Canada. Smoking cessation during pregnancy and relapse after childbirth in Canada. Ottawa (ON): Government of Canada; (modified 2016-07-07; accessed 2021-02-09). https://www.canada.ca/en/ public-health/services/publications/healthy-living/ smoking-cessation-during-pregnancy-relapse-afterchildbirth-canada.html

21. Blatt AJ, Lieberman JM, Hoover DR, Kaufman HW. Chlamydial and gonococcal testing during pregnancy in the United States. Am J Obstet Gynecol 2012;207(1):55.e1-8. DOI PubMed

22. Laga $M$, Plummer FA, Nzanze $H$, Namaara $W$, Brunham RC, Ndinya-Achola JO, Maitha G, Ronald AR, D'Costa LJ, Mati JK, Cheang M, Bhullar VB, Fransen L, Piot P. Epidemiology of ophthalmia neonatorum in Kenya. Lancet 1986;328(8516):1145-9. DOI PubMed

23. Whitcher JP, Srinivasan M, Upadhyay MP. Corneal blindness: a global perspective. Bull World Health Organ 2001;79(3):214-21. PubMed

24. Hammerschlag MR, Chandler JW, Alexander ER, English M, Chiang WT, Koutsky L, Eschenbach DA, Smith JR. Erythromycin ointment for ocular prophylaxis of neonatal chlamydial infection. JAMA 1980;244(20):2291-3. DOI PubMed

25. Wiesenfeld HC. Screening for Chlamydia trachomatis infections in women. N Engl J Med 2017;376(8):765-73. DOl PubMed

26. Plitt SS, Osman M, Sahni V, Lee BE, Charlton C Simmonds K. Examination of a prenatal syphilis screening program, Alberta, Canada: 2010-2011. Can J Public Health 2016;107(3):e285-90. DOI PubMed

27. Canadian Agency for Drugs and Technologies in Health. Screening for Chlamydia trachomatis and Neisseria gonorrhoeae during pregnancy: a health technology assessment. Ottawa (ON): CADTH; 2018. https://cadth.ca/ sites/default/files/pdf/ht0023_STIs_during-pregnancy.pdf 